Revista de Psicología de la PUCP. Vol. XIV. No 2. 1996

\title{
HERENCIA Y AMBIENTE: UNA APROXIMACIÓN INTERACTIVA HACIA EL TALENTO'
}

\author{
Franz J. Mönks ${ }^{2}$ \\ Universidad Católica de Nimega
}

El artículo presenta una reflexión crítica acerca de la relación interactiva entre la herencia y el ambiente en el desarrollo del talento desde la perspectiva de la psicología del desarrollo. En primer lugar se hace una reflexión respecto a aquello que constituye el desarrollo humano, para luego formular un modelo interactivo sobre el desarrollo del talentoso. Finalmente se plantean las necesidades socio/emocionales de los niños talentosos y los posibles problemas que estas pueden acarrear.

Palabras claves: superdotación, talentos, inteligencia, desarrollo humano y creatividad.

Heredity and environment: An interactionistic approach to giftedness.

This article presents a reflection about the interactive relation between heredity and environment in the development of giftedness from the developmental psychology point of view. First, there is a reflection about human development, to then formulate an interactive model of giftedness. Finally the social-emotional needs of the gifted are presented as well as the possible difficulties that these may cause.

Keywords: giftedness, talented, intelligence, human development and creativity.

1 El autor agradece a Sheyla Blumen por la traducción del presente artículo.

2 Es Profesor Principal del Departamento de Psicología del Desarrollo de la Universidad Católica de Nimega, Holanda y Director del Centro para el Estudio del talentoso en la misma universidad. Ha publicado y editado numerosos libros y artículos en revistas profesionales (holandés, inglés, alemán) en psicologia del desarrollo y educación del talentoso. Desde los inicios de la década del 80 ha centrado su interés en la enseñanza e investigación en el desarrollo y educación del individuo talentoso. En Octubre de 1996 fue reelegido Presidente del Consejo Europea de Altas Capacidades Intelectuales. Dirección: Prof. Dr. Franz Mönks, Center for the Study of Giftedness, University of Nijmegen, internet: monks@psych.kun.nl, P.O. Box 9104, 6500 Nijmegen, The Netherlands. 


\section{Introducción}

El desarrollo humano puede ser percibido como un proceso de hacerse miembro de una sociedad específica. Todos los individuos humanos nacen dentro de un mundo social. Ellos no sólo tratan de hacerse parte del ambiente social, sino que también deben tratar de realizar su potencial. El potencial individual y las necesidades sociales no siempre están en concordancia. Los padres por lo general tratan de desarrollar conductas aceptables en sus niños. En la realización de estos objetivos socialmente definidos, los padres y los profesores por lo general olvidan o no perciben las necesidades intelectuales específicas y emocionales de sus niños. Por lo tanto, es de suma importancia que los padres y los profesores comprendan el proceso de desarrollo humano y aquello que influye en estos procesos.

La psicología del desarrollo realiza una diferenciación entre el desarrollo cognoscitivo, sociolemocional y de personalidad. Es posible realizar una diferenciación entre el desarrollo cognoscitivo y socio/emocional, pero es imposible separarlos. Es evidente que el desarrollo cognoscitivo juega un rol central en el desarrollo integral del niño. Un buen ejemplo en este sentido es la conducta del apego temprano. El apego es visto como el primer lazo social que se desarrolla entre el infante y su cuidador(a) generalmente la madre. Para el desarrollo de la conducta de apego, sin embargo, el niño debe ser capaz de discriminar la cara de la madre de las otras caras, y el niño debe ser también capaz de reconocer a su madre como la misma persona que vio el día anterior y los días previos. Esto significa que el desarrollo socio/emocional no es causado por la discriminación y el reconocimiento, sino que estos son ingredientes básicos y necesarios para el desarrollo socio/emocional. Es verdad que las habilidades cognoscitivas y las destrezas intelectuales van a facilitar $o$ inhibir la interacción del niño con los otros. Esto puede ocurrir tanto en el hogar como en el colegio. 
Debemos dar una mirada cercana a los siguientes aspectos del comportamiento: (1)¿Cuál es el motor del desarrollo humano?, (2) ¿Qué es lo que significa el talento o la conducta talentosa?, y (3) ¿Qué es lo que conocemos acerca del desarrollo socio/emocional del niño y del adolescente talentoso?

\section{1) ¿Qué constituye el desarrollo humano?}

Existen diferentes teorías sobre la naturaleza del desarrollo humano; p.e. las teorías del aprendizaje o la teorías madurativas, las teorías cognoscitivas o las teorías psicoanalíticas. Todas las teorías concuerdan en que el desarrollo es visto como un proceso de cambio sobre el tiempo y que este cambio es el resultado de la interacción entre el individuo y su ambiente. La diferencia radica en la explicación de como ocurren los cambios: cuáles son los factores que determinan o causan el cambio. Para el teórico del aprendizaje los factores se encuentran ubicados externamente, mientras que para los teóricos madurativos los factores determinantes se encuentran internamente ubicados. Tanto para las propuestas psicoanalíticas como cognoscitivas, la maduración y el ambiente juegan un rol importante. Ambos son percibidos como aproximaciones interactivas. Para Freud, por ejemplo, la interacción entre el individuo y el ambiente es importante y hasta cierto punto decisiva para el desarrollo del Yo y Super Yo. Para Piaget, el desarrollo mental depende de la maduración y de las influencias externas.

En este punto podemos concluir que el desarrollo humano visto como un proceso de cambio continuo, ocurre a través de la interacción del individuo y su ambiente. Definimos desarrollo humano de la siguiente manera:

El desarrollo humano es un proceso dinámico de toda la vida. La interacción entre la naturaleza del individuo y el ambiente determina que tipo de conducta y que motivo de conducta emerge y se hace manifiesto.

Cada individuo vive en un período histórico específico, en un contexto socio/cultural determinado y en una familia dada. Todas estas variables ambientales pueden influenciar el desarrollo del individuo en direcciones opuestas, es decir en direcciones positivas y negativas. Depende esencial- 
mente de la creatividad y energía del padre el que, por ejemplo, un prodigio musical o un niño altamente capaz intelectualmente presente producciones sobresalientes. Cada talento necesita un ambiente de soporte y ambiente estimulante para su desarrollo. La condición óptima para cada desarrollo está expresada en el modelo de bondad de ajuste: la coincidencia apropiada de las características y necesidades individuales con un ambiente de soporte y comprensión. Esencialmente estamos hablando de como interactúan la herencia y el ambiente. Ellos no sólo influencian la conducta independientemente de otra, sino que la conducta es el resultado del interjuego dinámico entre estas dos fuentes fundamentales del desarrollo. La pregunta es entonces: ¿Cómo interactúan la herencia y el ambiente?

La genética conductual ha desarrollado numerosos conceptos importantes para hacer comprensible este pregunta compleja. Estos conceptos son: rango de reacción, canalización y selección de nicho. ${ }^{3}$

\section{Rango de reacción}

Cada persona responde de manera única a un rango de condiciones ambientales dadas. No existe una correspondencia simple de uno a uno entre nuestros genes y la conducta que desarrollamos. Esta es la razón por la que el genotipo de cada individuo establece sus propios límites superiores e inferiores de desarrollo. La figura 1, que se refiere a tres nińos hipotéticos, ilustra el rango de reacción con respecto a la inteligencia.

El niño A crece en un ambiente altamente estimulante, mientras que el niño $C$ crece en un ambiente extremadamente empobrecido.

"Un ambiente pobre dará como resultado una inteligencia más baja para el niño $C$ que para el niño $\mathrm{A}$, mientras que un ambiente favorecedor elevará el desempeño del niño A más allá de lo posible para el niño C" (Berk, 1989, p. 11). La figura muestra que cuando los ambientes varían, un genotipo simple puede producir diferentes fenotipos, y también que genotipos diferentes pueden llevar a fenotipos idénticos. Por ejemplo, el niño $C$ en un ambiente estimulante y el niño $B$ en un ambiente en desventaja: el resultado puede ser en ambos casos un puntaje de 100 . El

3. La posición y función de una especie particular o población en el entorno ecológico. 
Figura 1: El concepto Rango de Reacción (RR), mostrando la influencia simultánea de los genes y el ambiente. Los rangos de reacción (RR) Intelectuales para tres niños hipotéticos $(\mathrm{A}, \mathrm{B}$ y $\mathrm{C})$ en ambientes que varían desde restrictivos, no estimulantes hasta altamente enriquecedores (Berk, 1989, p.117).

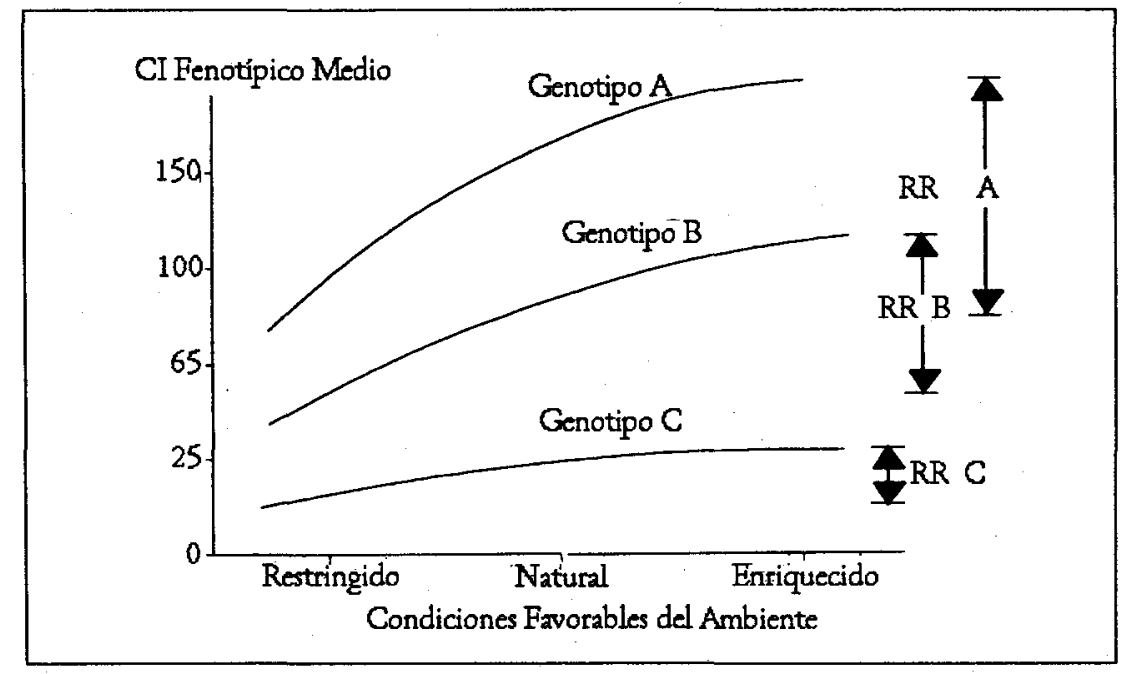

Rango de Reacción se aplica no sólo a la inteligencia, sino también a cualquier característica fenotípica. Más aún, este concepto asume una interdependencia compleja entre la herencia y el ambiente.

\section{Canalización}

Cierta conducta humana es fuertemente canalizada, por ejemplo el desarrollo prenatal: la cabeza, los ojos, los hombros, los brazos y las piernas, se desarrollan en este orden; el infante se sienta antes de poderse parar, balbucea antes de producir palabras, dibuja un círculo antes de dibujar un cuadrado. Sólo condiciones ambientales extremas pueden modificar estas conductas o causar su no aparición. Por el contrario, la inteligencia y la personalidad son canalizadas de manera menos fuerte y por lo tanto son más fáciles de modificar. 


\section{Selección de nicho}

Existen correlaciones genético/ambientales. Por lo general no es posible separar los factores genéticos y ambientales debido a que a menudo correlacionan unos con otros. Esto significa que las predisposiciones genéticas tienen alguna influencia en el ambiente al que estamos expuestos. Existen tres tipos de interacción genotípica/ambiental en el sentido de que existe una correlación entre los factores genéticos y ambiencales.

Correlación pasiva: el niño pequeño tiene poca influencia sobre su ambiente. Los padres determinan las condiciones de vida y proveen ambientes de crianza que sean compatibles con sus propios genotipos. $\mathrm{Si}$ a los padres les gusta leer, proveerán a sus hijos con un ambiente rico en lectura. Padres e hijos tienen genes en común, y por tanto es probable que los padres satisfagan las predisposiciones genéticas con este "ambiente de lectura". Por razones genéticas y ambientales se espera que los niños sean buenos lectores: correlación pasiva.

Correlación genéticolambiental evocativa: "Los niños evocan respuestas de orros que son influenciados por los genotipos de los niños, y las respuestas actúan para fortalecer su predisposición original" (Berk, 1989, p. 199). Por ejemplo, un niño amigable y sociable recibirá mayores respuestas sociales y estimulación que un niño tranquilo y pasivo. Las respuestas de "amistad" evocadas por el niño se espera que refuercen las predisposiciones del niño. En contraste, el niño autista aparentemente carece de un "programa social" genético.

Correlación genotípicolambiental activa: A medida que los nińos crecen, van al colegio y extienden sus experiencias más allá de sus familias, están cada vez más buscando ambientes y situaciones que sean compatibles con sus inclinaciones genéticas y que tengan las características de "bondad de ajuste". Ellos buscan de manera cada vez más activa por amigos con los cuales compartan intereses como deportes, música o intereses intelectuales.

Scarr y McCartney denominan "esta tendencia de individuos para escoger activamente ambientes que sean compatibles con sus predisposiciones genéticas niche-picking" (Berk, 1989, p.119). Ejemplos buenos sobre este tipo de elección activa de ambientes que se ajustan a las inclinaciones genéticas son presentadas por Howard Gardner en su libro Creating Minds (1993). 


\section{2) Qué significa el talento: un modelo interactivo}

En 1916 el psicólogo alemán William Stern señaló que el desarrollo de la superdotación intelectual depende del deseo de logro del individuo, en la perseverancia y en el ambiente de soporte. Con esta propuesta anticipó el punto de vista moderno sobre la superdotación. Por otro lado, el pionero en la investigación sobre la superdotación, Lewis Terman, quien inició y condujo el estudio longitudinal más intensivo que se haya desarrollado, creyó hasta el "día de su muerte" (Minton, 1988, p. 199) que cada individuo tiene una inteligencia determinada genéticamente que es estable a través del tiempo. Para la época en que tenía 77 años, en el año 1954, los datos empíricos de sus investigaciones genéticas lo convencieron que otros factores fuera de la inteligencia, tales como los factores de personalidad y los factores ambientales determinan de manera esencial el que un individuo logre o no desempeńos sobresalientes y/o el "éxito en la vida" (Terman, 1954).

Nosotros nos referimos al talento o a la alta capacidad como conceptos descriptivos. Los términos "talento", "alta capacidad", "muy hábil" o "elevada habilidad" los usamos como conceptos sinónimos. Una habilidad específica puede existir en las siguientes áreas: habilidad intelectual, social o habilidad de liderazgo, habilidad psicomotora o artística. Todos los talentos, sean excepcionales o promedios, requieren su atención y estimulación. En particular es necesario un ambiente social estimulante.

Nos referimos a un niño como talentoso cuando están presentes las siguientes características de personalidad: (1) altas habilidades intelectuales, (2) motivación y (3) creatividad. A partir de la consideración del desarrollo humano como un proceso interactivo, nuestro modelo también incluye los tres contextos más importantes del entorno social: familia, escuela y pares/amigos. Este modelo interactivo es una modificación y extensión del "Concepto de los Tres Aros" de Renzulli (1978), ver Figura 2.

Este modelo interactivo desarrollado por Mönks (Figura 3) visualiza la coincidencia de los factores más importantes que determinan el desarrollo de la conducta talentosa. Uno de los factores que están a la base y es crucial para el desarrollo exitoso es la competencia social. Es necesario 
Figura 2: La Concepción de Superdotación de los Tres Aros (Renzulli et al., 1981, p. 19).

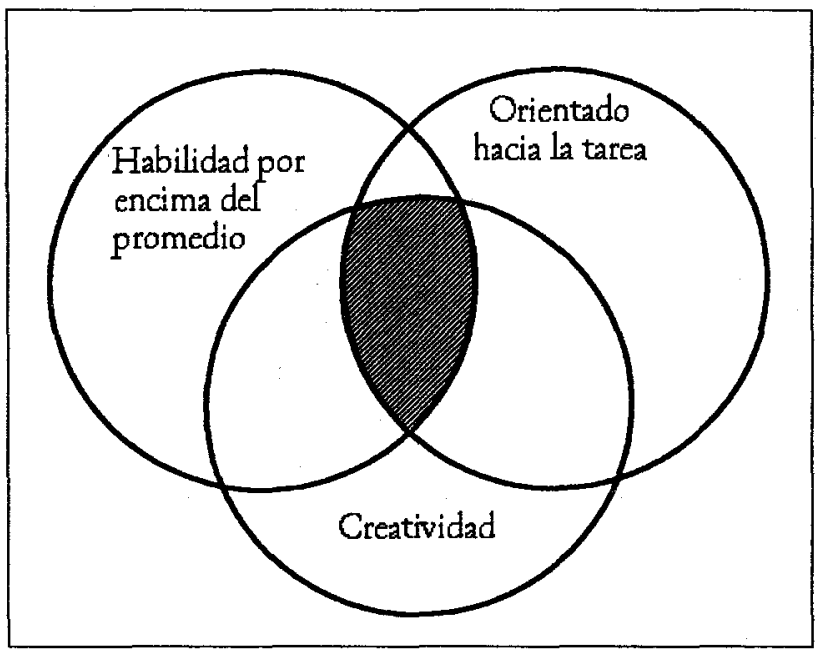

Figura 3: Modelo Multifactorial de Talento.

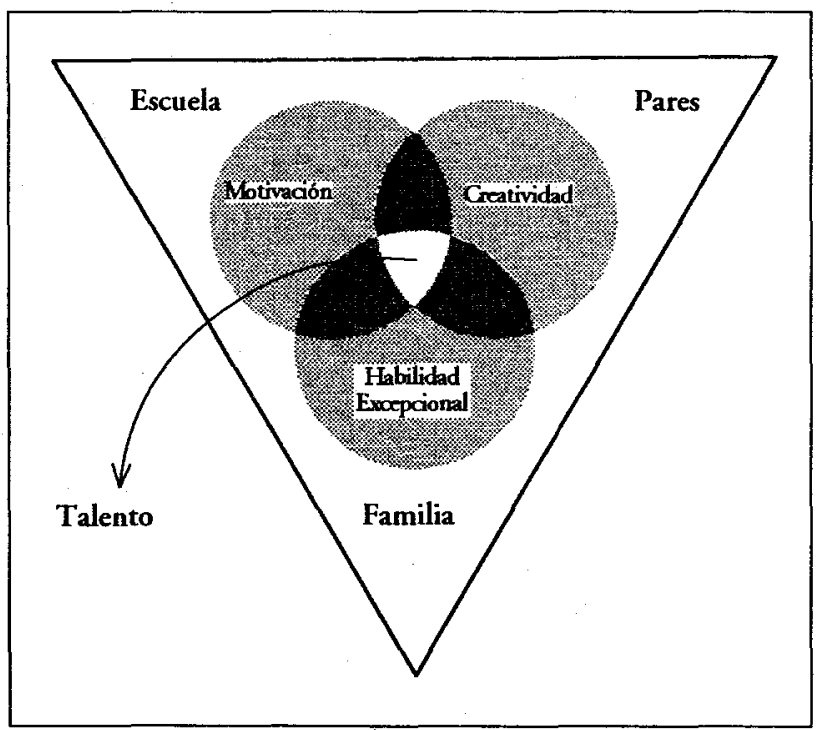


para saber afrontar las numerosas situaciones sociales cotidianas. Hasta cierto grado la competencia social es un don, pero necesita un entorno de soporte para su desarrollo. Como se señaló antes: el niño socialmente competente evocará conductas que estén en concordancia con su genotipo.

En la caracterización de los factores de este modelo interactivo se puede seńalar lo siguiente:

La Motivación incluye la "orientación hacia la tarea", perseverancia, toma de riesgos, y perspectiva de orientación futura en el tiempo. La motivación puede ser descrita como un constructo que monitorea (provee la energía necesaria), selecciona (lo que debe ser realizado o evitado; el planeamiento de los pasos correctos, p.e. Un componente cognoscitivo), y finalmente dirige la conducta. La motivación también significa que uno "ama" realizar una tarea o actividad, p.e. involucramiento emocional en la tarea.

La Alta habilidad intelectual significa que la inteligencia, medida por una prueba de CI o una prueba de logros académicos equivalente, está significativamente por encima del promedio.

Usualmente se utiliza como punto de corte para los puntajes de CI la puntuación 130 o más. Sin embargo, este punto de corte es relativo, debido a que la interpretación de la prueba depende en gran medida del análisis cualitativo. Es posible que un niño logre un puntaje de 120, pero que hayan indicadores que este puntaje no refleja el potencial total de un individuo. Por lo tanto es importante ser cuidadoso al dar el perfil "exacto". La gente tiende a creer con mucha facilidad que los números reflejan "exactitud" y "estabilidad".

La Creatividad se refiere a la capacidad individual de resolver tareas o problemas de manera independiente, productiva y original, ser capaz de encontrar más de una "solución correcta". La problemas de solución de situaciones y de encontrar problemas proveen las mejores oportunidades para la conducta creativa.

La interacción del nifo está principalmente enmarcada y determinada por el entorno social de la familia, del colegio y de los pares. En nuestras sociedades, usualmente, el niño nace dentro de un mundo social de familia 
y colegio, que son los entornos sociales dados. Sin embargo, a medida qut crece escoge a sus propios amigos, actividades, etc. Un par es una personc que es equivalente a él o ella a nivel de desarrollo y/o a nivel intelectual Esta igualdad forma la base para el intercambio mutuo, para la comuni. cación mutua. Las relaciones de pares proveen la oportunidad para compartir experiencias, para afrontar los problemas y para intercambiar ideas acerca de soluciones a problemas. Estas relaciones también proveen un ambiente de aprendizaje -especialmente durante la adolescencia- para la regulación e integración de las conductas tales como la agresión, sexualidad, y orientación de los valores. Los pares no son necesariamente amigos, pero los amigos son también pares en la mayoría de los casos. Las relaciones de pares son de importancia fundamental para el desarrollo saludable del individuo. La aceptación y/o rechazo de los pares tienen una influencia positiva o negativa en el desarrollo de la autoestima y del autoconcepto del individuo.

\section{3) El maquillaje cognoscitivo y las necesidades socio/emocionales de los nińos talentosos}

El nivel de destrezas cognoscitivas influenciará la conducta social y emocional. Desde el inicio los bebés recién nacidos muestran diferentes conductas en tres dominios básicos: actividad, irritabilidad y responsividad. Numerosos estudios han señalado que estas conductas dominan las diferencias de personalidad existentes entre los bebés desde temprana edad. Sin embargo no hay estudios centrados en la conducta temprana de niños superdotados. Numerosos estudios de casos e informes de padres indican, sin embargo, que muchos, pero no todos los niños superdotados demuestran niveles elevados de actividad e irritabilidad. Irritabilidad significa: algunos bebés lloran mucho, pero otros no; algunos bebés duermen poco y tienden a necesitar poco tiempo para dormir, pero otros son buenos durmientes; algunos bebés están siempre observando el ambiente, pero otros parecen no estar interesados en lo que ocurre en su entorno.

Es extremadamente importante para el desarrollo socio/emocional de cada niño y en particular para el niño talentoso que los educadores y los padres satisfagan estas características de personalidad desde temprana edad de manera apropiada. ¿Cómo podemos identificar las características 
(cognoscitivas) fuertes de los niños talentosos y qué tipo de problemas pueden estar asociados con éstas?.

Las características más significativas que son primariamente internas por naturaleza pero que pueden tener consecuencias externas son (ver Cuadro 1):

- guiar el uso de las habilidades propias (deseo de aprender).

- guiar la comprensión profunda (perfeccionismo).

- habilidad para ver posibilidades y alternativas diferentes (creatividad).

- intensidad emocional (involucramiento personal).

- preocupación en temas sociales y morales (idealismo).

En especial la habilidad para encontrar soluciones creativas en combinación con la intensidad emocional conlleva a que muchos niños superdotados tengan expectativas altas, poco realistas de si mismos. Para $15-20 \%$ de los individuos superdotados, en algún punto de su carrera académica, el perfeccionismo es una desventaja. Otra desventaja es el evitar la toma de riesgos: ellos perciben los problemas potenciales y tienden a evitar todo riesgo.

No es el maquillaje cognoscitivo que los dirige hacia los problemas socio/emocionales. Existen niños talentosos que desarrollan suavemente y sin ningún problema. Pero a veces ocurre que la combinación específica de la intensidad emocional, actitud idealista y la habilidad para ver las posibilidades y alternativas, crea problemas si el entorno social es incapaz de responder apropiadamente al individuo talentosos. En términos generales: los niños talentosos identificados y en programas escolares para talentosos están en menor riesgo de ciertos problemas emocionales y sociales que los alumnos no identificados. Pero es también posible que los alumnos talentosos no identificados y no atendidos funcionen bien. Esto significa que la identificación y los programas apropiados no son siempre una garantía de que no aparecerán problemas. Es incluso posible que los alumnos talentosos identificados estén en mayor riesgo que los no identificados. Debido a que casi todas las culturas presentan ambivalencia acerca de los individuos con habilidades cognoscitivas elevadas inusuales, tales individuos son observados con suspicacia. 
Cuadro 1: Características de los talentosos (Webb, 1993).

\begin{tabular}{|c|c|}
\hline Características & Problemas posibles \\
\hline $\begin{array}{l}\text { Adquiere y retiene información rápida- } \\
\text { mente. }\end{array}$ & $\begin{array}{l}\text { Impaciente con la lentitud de otros; no } \\
\text { le gustala rutina ni la ejercitación; puede } \\
\text { mostrar resistencia en la práctica } \\
\text { repetitiva de destrezas básicas; puede } \\
\text { hacer conceptos complejos de manera } \\
\text { indebida. }\end{array}$ \\
\hline $\begin{array}{l}\text { Actitud inquisitiva, curiosidad intelec- } \\
\text { tual; motivación intrínseca; búsqueda de } \\
\text { la significación. }\end{array}$ & $\begin{array}{l}\text { Realiza preguntas embarazosas; mucha } \\
\text { fuerza de voluntad; resiste la dirección; } \\
\text { parece excesivo en sus intereses; esperalo } \\
\text { mismo de los otros }\end{array}$ \\
\hline $\begin{array}{l}\text { Habilidad para conceptualizar, abstraer } \\
\text { y sintetizar, disfruta la solución de pro- } \\
\text { blemas y la actividad intelectual. }\end{array}$ & $\begin{array}{l}\text { Rechaza u omite detalles; muestra resis- } \\
\text { tencia ala práctica o ejercitación; cuestio- } \\
\text { nalos procedimientos de enseñanza ins- } \\
\text { trucción. }\end{array}$ \\
\hline $\begin{array}{l}\text { Disfruta organizando cosas y personas } \\
\text { dentro de una estructura y orden deter- } \\
\text { minado; busca la sistematización. }\end{array}$ & $\begin{array}{l}\text { Construye reglas o sistemas complicados; } \\
\text { puede parecer "mandón", rudo o domi- } \\
\text { nante. }\end{array}$ \\
\hline $\begin{array}{l}\text { Ampliación vocabulario y dominio ver- } \\
\text { bal; información amplia en áreas avanza- } \\
\text { das. }\end{array}$ & $\begin{array}{l}\text { Puede utilizar las palabras para escapar o } \\
\text { evitar situaciones; se aburre en el colegio } \\
\text { y con sus pares; es percibido como "el } \\
\text { sabelotodo". }\end{array}$ \\
\hline $\begin{array}{l}\text { Creativo e inventivo; le gusta buscar } \\
\text { nuevas formas de hacer las cosas. }\end{array}$ & $\begin{array}{l}\text { Puede interrumpir planes o rechazar lo } \\
\text { que está establecido; es percibido como } \\
\text { diferente y "fuera de onda". }\end{array}$ \\
\hline $\begin{array}{l}\text { Concentración intensa; largo rango de } \\
\text { atención en áreas de interés; conducta } \\
\text { dirigida hacia una meta; persistencia. }\end{array}$ & $\begin{array}{l}\text { Resiste la interrumpción; se olvida de las } \\
\text { cosas o de la gente en períodos de } \\
\text { focalización de intereses; terquedad. }\end{array}$ \\
\hline $\begin{array}{l}\text { Sensitividad, empatía hacia los otros; } \\
\text { deseo de ser aceptado por los otros. Per- } \\
\text { sistencia. }\end{array}$ & $\begin{array}{l}\text { Sensitividad hacia la crítica o rechazo de } \\
\text { pares; espera que los otros tengan valores } \\
\text { similares; necesidad de exito y reconoci- } \\
\text { miento; puede sentirse diferente } y \\
\text { alienado. }\end{array}$ \\
\hline $\begin{array}{l}\text { Energía elevada, alerta, ansioso; períodos } \\
\text { de esfuerzo intenso. }\end{array}$ & $\begin{array}{l}\text { Frustración con la inactividad; la ansie- } \\
\text { dad puede molestar a los otros; horarios; } \\
\text { necesita estimulación continua; puede ser } \\
\text { percibido como hiperactivo. }\end{array}$ \\
\hline $\begin{array}{l}\text { Independencia; prefiere el trabajo indi- } \\
\text { vidual; confia en sí mismo. }\end{array}$ & $\begin{array}{l}\text { Puede rechazar la intervención de padres } \\
\text { opares; no conformismo; puede ser poco } \\
\text { convencional. }\end{array}$ \\
\hline Fuerte sentido del humor. & $\begin{array}{l}\text { Velo absurdo delassituaciones; el humor } \\
\text { puede no ser comprendido por los pares; } \\
\text { puede convertirse en el "payaso de la cla- } \\
\text { se" para lograr atención. }\end{array}$ \\
\hline
\end{tabular}


Como se enfatizó anteriormente, el proceso de desarrollo es siempre un affair mutuo, afectando la conducta de los participantes en cada lado de la interacción. La lucha por la competencia se incrementa durante la infancia. Es importante que el niño tenga un espacio para la independencia o autonomía. Esto es especialmente importante para el autoconcepto del niño. Si el niño tiene la posibilidad de experimentar que él controla sus acciones, puede desarrollar lo que se denomina locus de contral interno como opuesto al locus de control externo, p.e. 'el niño experimenta y cree que su vida es controlada por fuerzas fuera de sí mismo. Este ejemplo demuestra que el desarrollo es esencialmente un proceso de descubrimiento a través de la interacción social de parte del niño. Cubriendo sus necesidades se le ayudará a desarrollar la creencia que puede controlar su vida un sentimiento básico para un autoconcepto positivo.

A medida que el nińo en crecimiento experimenta una variedad de situaciones, él descubre mucho acerca de sí mismo, acerca de los otros, y acerca del mundo en su totalidad. El deberá siempre encontrar soluciones para sus necesidades y deseos individuales, y para las demandas y requerimientos del entorno. Dentro de las conductas más visibles están las conductas prosociales (altruismo) y antisociales (agresión) y la dependencia. La pregunta es si los niños talentosos son diferentes, si sus destrezas cognoscitivas excepcionales influyen en estas conductas.

En un estudio de casos sobre pataletas, Kemmler (1957) observó cerca de 488 casos de pataletas durante 71 días. Ella visitó hogares, guarderías $e$ instituciones preescolares. Una de sus conclusiones principales es que las pataletas deben ser consideradas como una reacción, una reacción del niño contra una persona adulta que perturba su actividad, p.e. el niño está realizando una actividad y debe parar. El núcleo parece ser que existe una discrepancia entre las intenciones del niño y aquello que es capaz de hacer intelectualmente. Kemmler encontró que los niños talentosos en su muestra no mostraron conductas tipo pataletas. Su interpretación es que los niños talentosos saben lo que ellos son capaces de hacer, son capaces de juzgar su situación bastante bien. No existe una brecha entre la intención personal y la demanda social.

Como en el caso del apego, este nuevamente es un ejemplo de que hay una influencia de las destrezas cognoscitivas en la conducta social. Pero 124 
Kemmler encontró también que existen patrones individuales de conducta, que los niños irritables tienden a reaccionar de manera no reflexiva, sino más impulsiva, sean talentosos o no talentosos.

Este ejemplo muestra que hay nińos superdotados que no expresan conductas descontroladas, pero no todos los niños talentosos se comportan de la misma manera.

El desarrollo de la agresión y la dependencia está influenciada de muchas maneras por la interacción con los pares. Un par es una persona igual en términos de desarrollo. Un amigo es por lo general un par, pero no todos los pares son amigos. La amistad existe sobre la base de los intereses mutuos, intercambio de ideas, lealtad y ausencia de competencia y de deshonestidad. Cada individuo necesita relaciones de pares y de amigos para su desarrollo social y emocional. La adolescencia es un período para establecer amigos cercanos. Esto es también válido para los adolescentes talentosos. El problema que existe por lo general es que los individuos talentososno encajan dentro de la edad graduada en el sistema escolar, ellos están por lo general más lejos en comparación de sus condiscípulos del mismo salón de clases. La disposición de amigos posibles y de pares intelectuales es por lo general un problema para los individuos talentosos jóvenes. Desde que los seres humanos no sólo nacen dentro de un mundo social, sino que tratan también de pertenecer a éste y ser parte integral del mismo, vemos que los niños talentosos desarrollan conformidad hacia las normas y conductas que son dominantes. La intención de pertenecer al grupo es más fuerte que el deseo de desarrollarse a sí mismo según sus propias necesidades.

En un artículo reciente Mönks (1992) llamó la atención hacia el desarrollo psicosocial de los adolescentes. En su modelo de desarrollo psicosocial describe las condiciones universales y los dominios de conducta universal. Durante la adolescencia, los cambios básicos tienen lugar en los estados biológicos de la persona, en sus capacidades cognoscitivas y en su posición social. Más aún, una revisión profunda de la literatura sugiere que existen seis dominios de conducta que son considerados como universales: apego, amistad, sexualidad, logro, autonomía e identidad. Las transformaciones de estos dominios de conducta no son vistas como únicas por el 
período adolescente; ellos existen a lo largo de la vida. La investigación, sin embargo, nos dice que los cambios en éstos dominios de conducta durante la adolescencia son por lo general muy específicos y típicos y sin ningún precedente anterior o posterior al período adolescente. Si bien podemos distinguir estos seis dominios de conducta, no los podemos separar: las transformaciones en cada dominio están relacionadas de manera recíprocamente interactiva, hacia transformaciones en otros dominios.

Si revisamos la literatura respecto a las diferencias en estos dominios de conducta entre los adolescentes superdotados y no superdotados, encontraremos diferencias notables en dos dominios, identidad y en particular en el dominio de logro. La identidad del individuo deriva de las experiencias sobre sus capacidades, la idea acerca de quien es y su autoconcepto. Haciendo una distinción entre el autoconcepto general, social y académico, uno puede identificar las diferencias entre los adolescentes superdotados y no superdotados. Los adolescentes superdotados con logros presentan un autoconcepto académico fuerte comparado con los adolescentes no superdotados. Los adolescentes superdotados con bajo rendimiento presentan un autoconcepto académico bajo, que a su vez tiene un impacto en el autoconcepto general y social de estos individuos. Estos sentimientos negativos sobre sus capacidades contribuyen a un concepto de identidad inferior y tienen un impacto en el funcionamiento de estos adolescentes.

El hallazgo más significativo de la investigación es la diferencia en el dominio cognoscitivo y las consecuencias de esta diferencia. Los adolescentes talentosos son conocidos como poseedores de elevados estándares de excelencia. Pero el lograr los estándares de excelencia preferidos por los adultos puede constituir una calificación negativa para la aceptación del grupo de pares. Por lo tanto, este dominio de conducta es una fuente de conflicto para los adolescentes talentosos: el conflicto entre la aceptación social y el logro.

Generalmente existen enormes diferencias entre los adolescentes talentosos y no talentosos en el dominio cognoscitivo. Después de todo es en este dominio que los (intelectualmente) talentosos son definidos. Los preadolescentes talentosos son ya capaces de producir operaciones formales 
y de pensar en niveles abstractos, que según la literatura es "normal" a partir del período adolescente. Como una consecuencia de la brecha en las diferencias cognoscitivas, deben existir diferencias sociales en el desarrollo entre los adolescentes talentosos y no talentosos. Los talentosos pueden no estar tan avanzados en la conducta social como lo puede estar en el razonamiento social. Más aún la brecha entre su pensamiento adulto y los límites establecidos por las restricciones relacionadas con la edad es una preocupación importante de padres y profesores. Entonces, tal como se puede esperar en el modelo general del desarrollo adolescente, estas capacidades de razonamiento avanzadas pueden tener una influencia en lo que hemos denominado el dominio de conducta universal. Como se señaló anteriormente, las transformaciones en cada dominio están relacionadas, de manera recíprocamente interactiva, hacia transformaciones en otros dominios.

\section{Conclusiones}

1. El desarrollo psicológico es básicamente un proceso interactivo y el resultado de interacciones entre el individuo y su ambiente.

2. Los bebés recién nacidos son diferentes en tres dominios de conductas distintas: actividad, irritabilidad y responsividad.

3. Los recién nacidos talentosos, aunque no todos, demuestran elevados niveles de actividad, irritabilidad y responsividad.

4. Los padres y educadores tienen una gran responsabilidad en el proveer de una educación e instrucción apropiada para satisfacer las necesidades específicas de los niños talentosos.

5. El período adolescente está caracterizado por transformaciones decisivas en el desarrollo socio/emocional. La lucha por la aceptación social inhibe, por lo general, el desarrollo de la personalidad en lo individuos talentosos.

6. El modelo de Bondad de Ajuste provee un marco óptimo para el desarrollo individual: p.e. la interacción entre el individuo y su ambiente es mutuamente reforzado, estimulado y enriquecedor. 


\section{Referencias}

Berk, L.E. (1989). Child Development. Boston/Toronto: Allyn and Bacon. Gardner, H. (1993). Creating Minds. Nueva York: Basic Books.

Kemmler, L. (1957). Untersuchungen über den frühkindlichen Trotz. Psychologische Forschung, 25, 2279-338.

Minton, H.L. (1988). Lewis M. Terman - Pioneer in Psychological Testing. Nueva York: New York University Press.

Mönks, F.J. (1992). Development of the Gifted: Focus on Adolescence. In Wu-tien Wu, Ching-Chih Kuo \& Joyce Steeves (Eds.), Proceedings of The Second Asian Conference on Giftedness: Growing Up Gifted and Talented (pp. 303-312). Taipei: National Taiwan Normal University. Renzulli, J.S., Reis, S.M. \& Smith, L.H. (1981). The revolving door identification model. Mansfield Center Connecticut: Creative Learning Press.

Stern, W. (1916). Psychologische Begabungsforschung und Begabungsdiagnose. In P. Petersen (ed.), Der Auftieg der Begabten (pp. 105-120). Leipzig: Teubner.

Terman, L M. (1954). The discovery and Encouragement of Exceptional Talent. American Psychologist, 9, 221-230.

Webb, J.T. (1993). Nurturing Social-Emotional Development of Gifted Children. In K.A. Heller, F.J. Mönks y A.H. Passow (Eds.), International Handbook of Research and Development of Giftedness and Talent (pp. 525-538). Oxford: Pergamon Press. 